\title{
Multiple Tuberous Xanthomas A Rare Case in Young Female
}

\author{
Dr. Avinash Mane*, Dr. S. S. Kumbhar, Dr. Sunil V. Jagtap, Dr. Nitesh Nasre, Dr. Sonam Billawaria
}

Krishna Institute of Medical Sciences Deemed To Be University, NH4, Pune - Bangalore Highway, Dist.Satara, Agashivnagar, Malkapur, Maharashtra, 415539, India

DOI: $10.36347 /$ sjmcr.2020.v08i07.021

| Received: 16.07.2020 | Accepted: 24.07.2020 | Published: 28.07.2020

*Corresponding author: Dr. Avinash Mane

Abstract

Case Report: A 28-year-old female presented with multiple subcutaneous nodules since last five years. Initially, lesions started on the back, hands and gluteal region. They were slowly progressive, persistent and asymptomatic. Patient was unmarried and her only concern was cosmetic appearance, so she underwent excisional biopsy of the lesion from gluteal region in our hospital. Routine haematological investigations and coagulation profile was normal. Grossly, we received yellowish, soft, cheesy mass measuring 1.8 x $1.1 \times 1.0 \mathrm{~cm}$. Cut section showed soft, yellowish, cheesy areas. Microscopic study revealed skin showing epidermis and dermis lined by stratified squamous epithelium. Epidermis was thin with no dysplasia. Dermis showed diffuse infiltration of foamy macrophages along with many classical Tuoton type giant cells. Based on these findings and clinical details, diagnosis of tuberous xanthoma was offered. Discussion: Xanthoma is a localised collection of tissue histiocytes containing lipids. It is a pseudotumor which particularly occurs in response to alterations in lipid metabolism. Tuberous xanthomas generally present as discrete painless nodules or large plaque like lesions of the subcutis. In our patient, lipid profile was found to be deranged and cholesterol was on higher side i.e. $380 \mathrm{mg} / \mathrm{dl}$. Because of prompt diagnosis, patient was shifted on cholesterol lowering agents to prevent cardiovascular complications. Conclusion: In conclusion, we are presenting a case of Multiple Tuberous Xanthomas in a young female not only for its histopathological diagnosis but also for putting more emphasis on correction of lipid profile through prompt administration of cholesterol lowering agents. This will lower the risk of mortality due to cardiovascular complications.

Keywords: subcutaneous nodules, coagulation profile soft, Xanthoma, histiocytes.

Copyright @ 2020: This is an open-access article distributed under the terms of the Creative Commons Attribution license which permits unrestricted use, distribution, and reproduction in any medium for non-commercial use (NonCommercial, or CC-BY-NC) provided the original author and source are credited.

\section{INTRODUCTION}

Xanthoma is a symptom rather than a disease, which arises due to a primary error in lipid metabolism or may even arise without any underlying disorder, clinically manifesting as soft to firm papules, plaques or nodules at various sites. There are several types of Xanthomas Eruptive, Tuberous, Tendinous, Planar and Disseminated. Xanthomas can arise either due to extravasated lipids that are taken up by macrophages, resulting in foam cells or foam cells developing as a result of in situ lipid synthesis by macrophages [1].

Prompt diagnosis and treatment may help to prevent dreadful side effects like Coronary Artery Disease and Pancreatitis.

We are presenting a case of Tuberous Xanthomas on multiple body sites in a 28 year old female (Fig 1, 2).

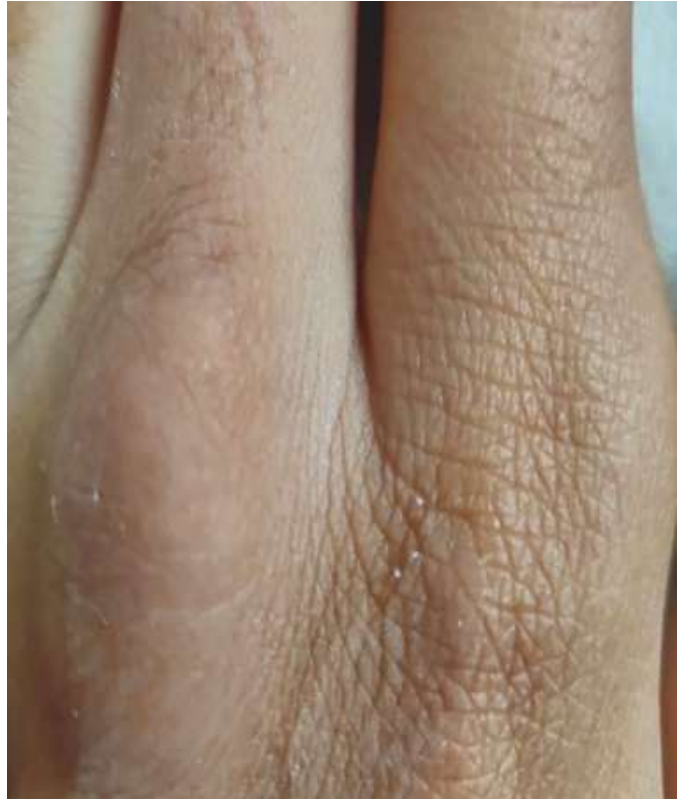

Fig-1: Multiple swellings over Hands 


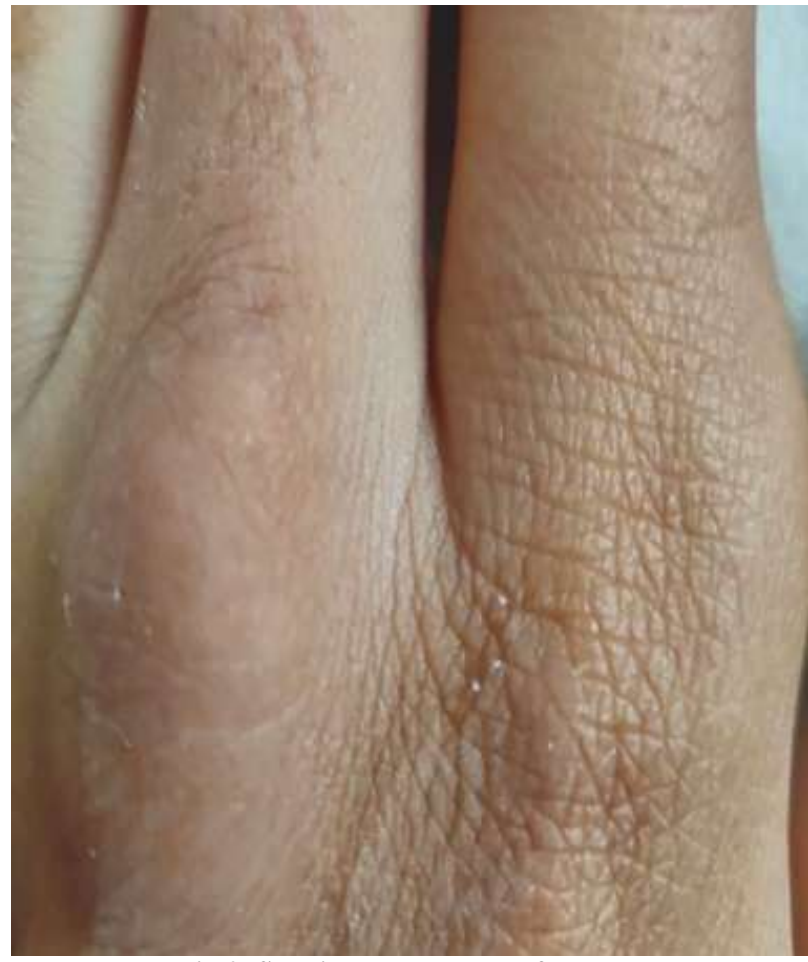

Fig-2: Swelling over dorsum of Hands

\section{Case Report}

A 28-year-old female presented with multiple subcutaneous nodules since last five years. Initially, lesions started on the back, hands and gluteal region. They were slowly progressive, persistent and asymptomatic. Patient was unmarried and her only concern was cosmetic appearance, so she underwent excisional biopsy of the lesion from gluteal region in our hospital. Routine haematological investigations and coagulation profile was normal.

\section{Pathological Findings}

Grossly, we received yellowish, soft, cheesy skin coloured mass measuring $1.8 \times 1.1 \times 1.0 \mathrm{~cm}$ (Fig3). Cut section showed soft, yellowish, cheesy areas (Fig-4).

Microscopic study revealed skin showing epidermis and dermis. Epidermis is lined by stratified squamous epithelium. Epidermis was thin with no dysplasia. Dermis showed diffuse infiltration of foamy macrophages along with many classical Tuoton type giant cells (Fig 5 to 7).

Based on these findings and clinical details, diagnosis of tuberous xanthoma was offered.

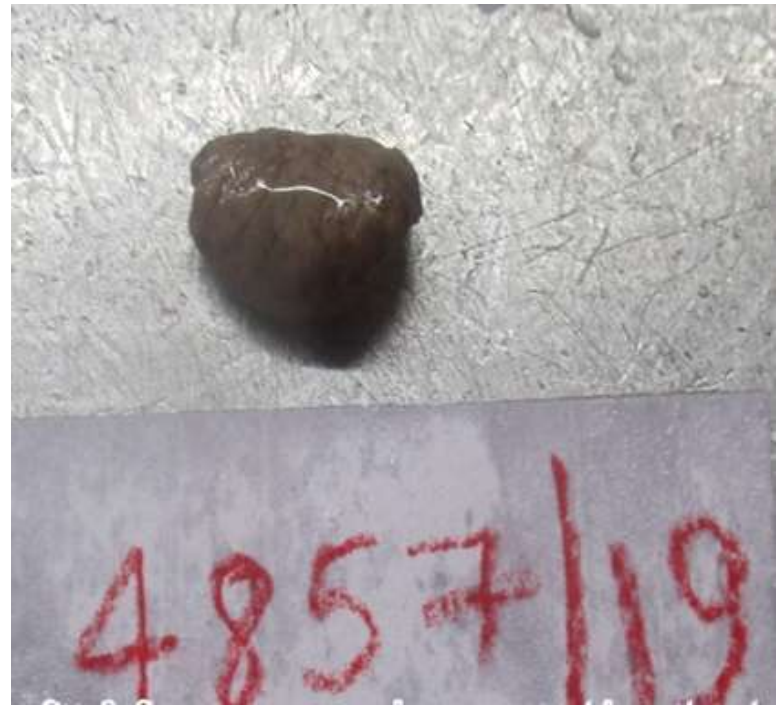

Fig-3: Gross appearance of mass received from gluteal region

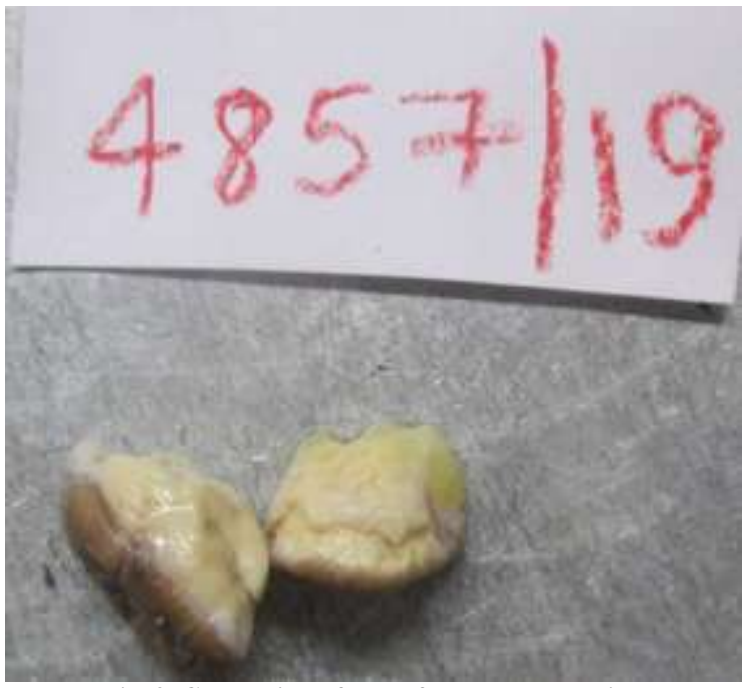

Fig-4: Cut section of mass from gluteal region

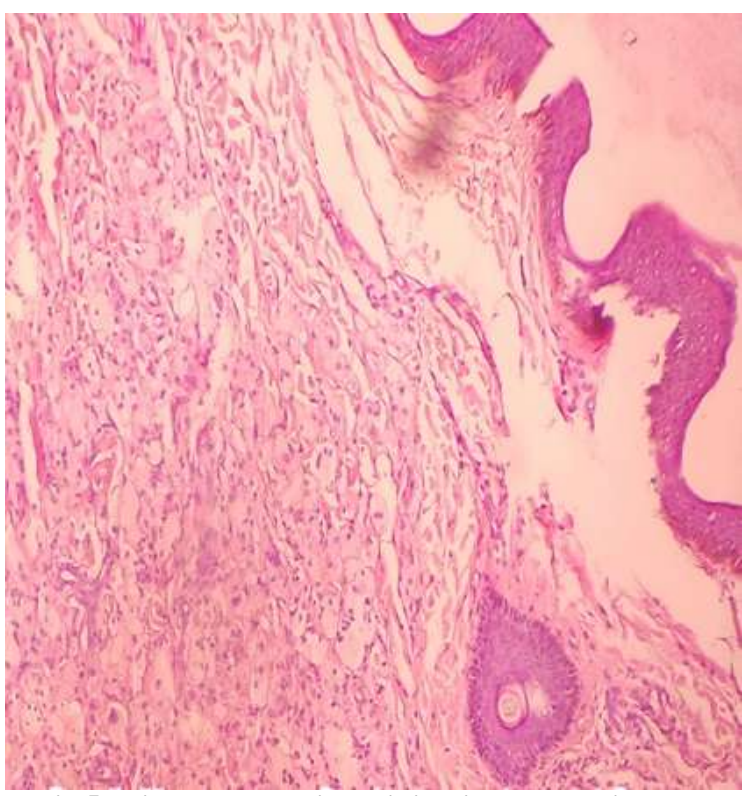

Fig-5: Microscopy - Epidermis is thin and Dermis shows infiltration by foamy macrophages 


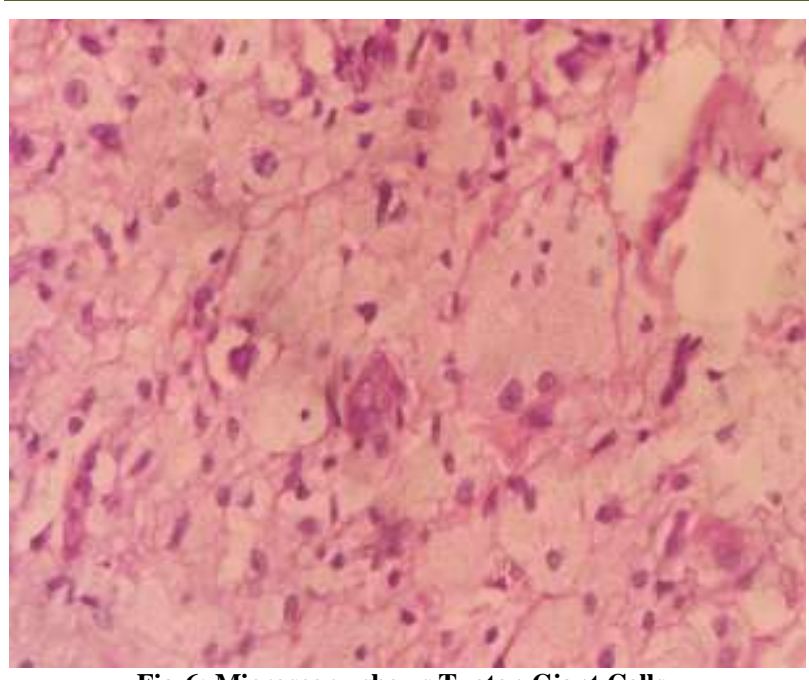

Fig-6: Microscopy shows Tuoton Giant Cells

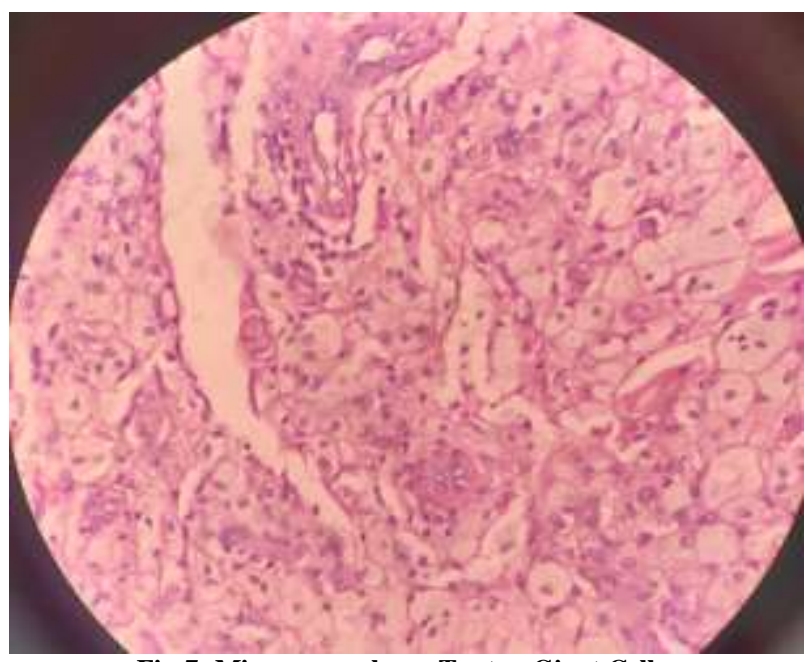

Fig-7: Microscopy shows Tuoton Giant Cells

\section{DISCUSSION}

Xanthomas are infiltrates of the skin that are yellow to brown red in colour and result from infiltration of the dermis by lipid containing foamy macrophages [2].

Tuberous xanthomas present as discrete, occasionally multilobated painless nodules. The most commonly xanthomas are associated abnormal lipid metabolism. Familial Hypercholesterolemia is one of the important genetic disorder usually associated with tendinous xanthomas [3].

Xanthomas consist of cholesterol, cholesterol esters, triglycerides, phospholipids and numerous lipidladen foamy macrophages [4].

Cutaneous xanthomas are designated according to their appearance and clinical presentation. Eruptive xanthomas are small, yellow papules.

Tuberous xanthomas are large plaque-like lesions of the subcutis, usually located on the buttocks, elbows, knees, and fingers. Plane xanthomas occur in skinfolds, such as the palmar creases. Xanthelasmas are xanthomas of the eyelids [5].

Previously, xanthomas were considered as a neoplastic lesion, but their association with hyperlipidemic states confirms that these are benign reactive lesions [6].

The pathogenesis suggested in such lesions are that the lipids leave the vascular compartment, traverse small vessels, and enter the macrophages of soft tissue. Once ingested by macrophages the lipoprotein is degraded to lipid, and the lipid is released to the extracellular space. The fibrosis characteristic of mature or longstanding xanthomas is believed to be secondary to the fibrogenic properties of extracellular cholesterol.

Histopathologically close differential diagnosis are Dermatofibroma and other benign soft tissue tumors.

Our patient was 28 years old female having multiple, discrete, painless nodules all over the body.

Microscopy examination classically revealed dermis infiltrating lesion in the form of foamy macrophages and tuoton type giant cells which promoted us to give a diagnosis of Multiple Tuberous Xanthomas.

Clinical diagnosis in our case was soft tissue tumors probably Lipomas or Neurofibromas.

We insisted for lipid profile levels which showed severe hypercholesterolemia $(380 \mathrm{mg} / \mathrm{dl})$. In our case hypercholesterolemia is the reason for Tuberous Xanthomas. Because of prompt histopathological diagnosis patient was shifted on statins (cholesterol lowering agents) to prevent cardiovascular complications.

\section{Conclusion}

In conclusion, we are presenting a case of Multiple Tuberous Xanthomas in a young female not only for its histopathological diagnosis but also for putting more emphasis on correction of lipid profile through prompt administration of cholesterol lowering agents. This will lower the risk of mortality due to cardiovascular complications.

\section{REFRENCES}

1. Rajashekara Babu AV, Santhosh S, Shivaswamy S. Giant tuberous xanthomas in a case of type IIA hypercholesterolemia. Journal of Cutaneous and Aesthetic Surgery. 2012 Jul;5(3):204-206.

2. Singh AJ, Sikarwar S, Jatav OP, Saify K. Normolipemic tuberous xanthomas. Indian J Dermatol. 2009 (Apr-Jun); 54(2):176-179. 
3. Zak A, Zeman M, Slaby A, Vecka M. Xanthomas: Clinical and pathophysiological relations. Biomed Pap Med Fac Univ Palacky Olomouc Czech Repub. 2014; 158:181-188.

4. Szalat R, Arnulf B, Karlin L, Rybojad M, Asli B, Malphettes M, Galicier L, Vignon-Pennamen MD, Harel S, Cordoliani F, Fuzibet JG. Pathogenesis and treatment of xanthomatosis associated with monoclonal gammopathy. Blood. 2011 Oct 6;118(14):3777-84
5. Sethuraman G, Sugandhan S, Sharma G, Chandramohan K, Chandra NC, Dash SS, Komal A, Sharma VK. Familial homozygous hypercholesterolemia: Report of two patients and review of the literature. Pediatr Dermatol. 2007; 24:230-234.

6. Marcoval J, Moreno A, Bordas X, Gallardo F, Peyrí J. Diffuse plane xanthoma: clinicopathologic study of 8 cases. Journal of the American Academy of Dermatology. 1998 Sep 1;39(3):43942 . 